\title{
c
}

Ambiente \& Edueaçŏo

Rerlikn de Educaço hmbiental

E-ISSN 2238-5533

Volume 25 | ํㅡ 3 | 2020

\section{APRESENTAÇÃO DO DOSSIÊ \\ FENÔMENOS AMBIENTAIS COSTEIROS EM TEMPOS DE MUDANÇAS AM- BIENTAIS GLOBAIS}

José Vicente de Freitas
Professor Titular da Universidade Federal do Rio Grande (FURG).
Integra o Instituto de Ciências Humanas e da Informação (ICHI).
Pesquisador do Programa de Pós-Graduação em Educação Ambiental.

Líder do Grupo de Pesquisa Ribombo: Gestão e Educação Ambiental, Mudanças Climáticas e os Objetivos do Desenvolvimento Sustentável.

Consultor Ad Hoc de Organismos Internacionais.

ORCID ID: $\underline{0000-0001-7121-9921}$

\section{Sandra Regina Lestinge}

Professora Adjunta da Universidade Federal do Piauí (UFPI), Campus CPCE. Autora e Tutora do PET "Intervenção Socioambiental em Uruçuí-Uma" Vencedora do Prêmio Santander Universidades (2012). Pesquisadora vinculada ao Grupo de Pesquisa Ribombo. Integrante do Projeto Conexão Água (Prêmio CNMP 2020) da 4ạ CCR/ 3a Região/MPF.

ORCID ID: $\underline{0000-0002-4192-8177}$

Ribombo

Grupo de Pesquisa e Estudos em Educação e Gestão Ambiental, Mudanças Climáticas e Objetivos do Desenvolvimento Sustentável em Áreas Litorâneas. 
No conjunto de indicadores e ocorrências que caracterizam a grave e aguda crise socioambiental contemporânea que transpassa a vida de todos nós, homens e mulheres que fazemos deste país a nossa morada, um evento, em especial, acabou marcando o ano de 2008: a denominada "Tragédia do Morro do Baú". Mas é provável, em função do tempo que separa este acontecimento do presente, que os significados e as fissuras deste extremo climático já tenham se apagado da nossa memória coletiva.

Em traços grossos, a trágico roteiro pode ser resumido da seguinte forma: no dia 22 de novembro, numa noite de sábado, as consequências de chuvas intensas no Vale do Rio Itajaí-Açu atingiram e riscaram do mapa a comunidade conhecida como Morro do Baú, situada no município de Ilhota, no Estado de Santa Catarina. Com precipitações acima do normal que ocorreram num curto espaço de tempo e o consequente encharcamento e saturação do solo, morros vieram abaixo, diluíram-se, literalmente, e uma combinação de água e lama, arrastou a vida e a história de uma comunidade inteira que, devastada, registrou 47 mortes.

Mesmo considerando que a localização do Estado de Santa Catarina favorece a variedade de eventos climáticos (ponto onde se chocam as massas de ar quente, que vem da região tropical, e o ar frio, que se desloca da região polar), os especialistas já associaram o desastre, naquele momento, ao contexto das mudanças climáticas provocadas pelo aquecimento global.

Assim como o evento ocorrido no Morro do Baú, nessa mesma categoria de eventos extremos associados as mudanças climáticas podemos enquadrar fenômenos como as chuvas intensas, inundações costeiras, vendavais, ondas de calor, mudanças nos ecossistemas, ocorrência de baixíssimas temperaturas, tornados e furacões, marés meteorológicas e grandes secas, todos fenômenos que representam forças com grande poder de destruição.

E podemos relembrar situações similares as do Morro do Baú, como o Furação Catrina, de 2004, o primeiro registrado no Atlântico Sul; a seca de 2012 a 2017 no semiárido, considerada a pior já ocorrida na História do Brasil (segundo levantamento do Instituto Nacional de Meteorologia - Inmet); os temporais que recorrentemente alcançam as regiões metropolitanas densamente povoadas no sudeste do país, deixando para trás prejuízos econômicos, mor- 
tes, desabrigados e uma variada gama de problemas, dos relacionados a infraestrutura e funcionalidade das cidades aos de natureza social.

Se deslocarmos nossa mirada para fora das nossas fronteiras, os exemplos vão se multiplicando e revelando a gravidade, a escala e a complexidade do problema. A rigor, nenhuma parte do globo tem sido poupada dos impactos dos eventos climáticos extremos.

De acordo com dados do Emergency Events Database (uma base de dados de desastres naturais e tecnológicos), somente no ano de 2018, aproximadamente 57,3 milhões de pessoas foram afetadas ao redor do planeta. A título de ilustração, rememoramos aqui alguns desses eventos: no hemisfério norte, o extremo frio alcançou até - 50 C no meio-oeste e noroeste estadunidense; a Austrália e países europeus vem registrando ondas intensas de calor; os furacões Michael e Florence na costa oeste dos Estados Unidos; os tufões Jebi e Trami no Japão; os Incêndios na Califórnia; a tempestade Emma; a onda de frio "Besta do Leste", na Europa; as extensas enchentes na China e na Índia. E como dado já consolidado, estima-se que 394 eventos climáticos extremos ocorreram somente ao longo de 2018.

Com um cardápio tão variado de cases espalhados mundo afora, evocamos o evento do Morro do Baú como uma referência que exemplifica e resume as diferentes facetas de uma tragédia relacionada a um evento climático extremo por conta de uma narrativa que, pouco tempo depois do fato ocorrido, foi possível registrar. Trata-se um de um depoimento de uma residente local, sobrevivente, que pelos elementos expostos na sua fala, escancara o quão estamos desatentos e desinformados sobre o tema; desvela o completo despreparo e ausência de planejamento, tanto do poder público quanto da sociedade civil, para o enfrentamento desses eventos.

Mas vamos nos ater apenas a uma das expressões que marcam esta narrativa, forte, expressiva e sensível, que pode ser tomada como um dos significados que caminham juntos com os desastres e riscos a que estamos sujeitos. Em determinada altura da fala, a narradora, sobre as perdas, comenta: "não é somente a sua casa, o seu porto seguro, seus familiares, vizinhos e amigos que você perde. O que fica para trás, o que desaparece, é a sua histó- 
ria e a memória das pessoas que construíram uma identidade na relação com aquele lugar"!

Em síntese, referia-se, entre tantos outros argumentos tão prenhe de sentidos, a memória rizomática construída na trama cotidiana da experiência humana em cumplicidade com todos os elementos naturais que davam cor ao lugar, vivências que naquele momento, abruptamente, perderam suas raízes; pertencimento esfacelado.

Nesse contexto de mudanças ambientais globais e mudanças climáticas, uma pergunta acaba necessariamente se impondo. Como estamos nos posicionando, institucionalmente, coletiva e individualmente diante de um cenário presente e futuro tão incertos? Nossa perspectiva de incertezas e, portanto, de diferentes cenários de futuro, assemelha-se ao mistério ultimato da esfinge de Tebas, que a mitologia grega nos legou como herança. Com o problema posto para a sociedade planetária, o equacionamento do desafio pode indicar o fim ou o recomeço da vida. O "Decifra-me ou Devoro-te" se constitui numa metáfora oportuna e necessária para refletirmos sobre o futuro provável, o futuro possível e o futuro desejado

Até este momento, o movimento de construção de alternativas as perspectivas de desastres é ainda lento em detrimento a urgência. Alguns governos começam a atribuir importância e atenção que o tema requer, definindo políticas, elaborando planos de ação, desenvolvendo campanhas de educação socioambiental, estruturando planos de adaptação e mitigação, procurando organizar suas cidades e preparando sua infraestrutura. Ainda é significativo o grupo dos negacionistas e da inação. Dois cavaleiros do apocalipse, George W. Bush e Donald Trump, não ofereceram oportunidades para um posicionamento redentor e reconciliador dos Estados Unidos com a saúde do planeta. No Brasil, os esforços para integrar a questão climática em suas políticas públicas deslocou-se da condição de algumas iniciativas adotadas no contexto de construção de um projeto de sociedade mais progressista, para uma posição absolutamente conservadora e arredia a qualquer iniciativa relacionada ao tema. $\mathrm{A}$ passos largos, com braços fortes, o país passou a "desafiar o nosso peito a própria morte".

Mesmo que recaia alguns questionamentos sobre como trata os conflitos de interesses entre os Estados no que diz respeito as mudanças climáticas, o 
Intergovermmental Panel on Climate Change (IPCC), tem oferecido estudos importantes sobre o aquecimento global e a mudança no nosso sistema climático. Por sua vez, um estudo do Institute for Public Policy Reserarch (IPPR) sobre ocorrência de enchentes e incêndios ao redor do mundo desde 1950, nos levam a concluir que estamos entrando numa era de rápidas mudanças ambientais, condição que definem como 'idade do colapso ambiental".

Ocorrências climáticas extremas já em curso e em processo de intensificação em todo o planeta, os estudos apresentados por instituições e especialistas, o resultado de debates em fóruns reconhecidos internacionalmente e eventos muitos próximos ou que nos afetam diretamente, ou que nos tocam profundamente, mesmo que distantes, nos remete a um quadro trágico que já a algum tempo vem sendo pintado sobre o "Nosso Futuro Comum".

Quando o Grupo de Pesquisa Ribombo propôs um Dossiê Especial da Revista Ambiente e Educação dedicado ao tema "FENÔMENOS AMBIENTAIS COSTEIROS EM TEMPOS DE MUDANÇAS AMBIENTAIS GLOBAIS”, o propósito foi exatamente o de somar-se aos esforços que vem sendo realizado pela comunidade acadêmica brasileira e internacional no sentido de promover a disseminação da informação e fomentar o debate, gerando subsídios e referências para um posicionamento comprometido, do ponto de vista ético, moral e político com o nosso tempo.

Por outro lado, se lançar a organização deste dossiê temático também se constituía em oportunidade para dialogar e intercambiar experiências com outras instituições, pesquisadores, seus projetos, suas preocupações e resultados alcançados, buscando compreender seus lugares de fala e suas perspectivas. Motivou-nos, igualmente, colaborar no processo de internalização do tema no âmbito do Programa de Pós-Graduação em Educação Ambiental, quiçá inspirando novas e necessárias pesquisas, gerando acúmulos e mesmo intentando consolidá-lo como um dos motes das nossas linhas de pesquisas, todas assentadas na educação ambiental como área de concentração.

Como resultado final do chamamento público aberto para submissão de contribuições, apresentamos ao público o presente dossiê temático composto N por 10 artigos e 1 Mostra fotográfica que abordam as mudanças ambientais globais a partir de enfoques diversos, leque que nos proporciona a real dimen- 
são do alcance das preocupações que o tema advoga. Foram acolhidos textos de pesquisadores(as) com diferentes níveis de experiência investigativa e oriundos de distintas áreas do conhecimento. Para nossa alegria e honra, a oportunidade do dossiê viabilizou a participação de especialistas dos dois lados do Atlântico, envolvendo pesquisadores e instituições brasileiros e portugueses, reforçando assim um espaço coletivo de trabalho que vem se constituindo pela Rede Braspor (Rede de Pesquisadores Brasileiros e Portugueses dedicados aos estudos costeiros).

Nosso reconhecimento e agradecimento aos esforços empenhados na concretização deste dossiê.

Aos interessados, fica o convite à leitura e ao diálogo crítico e solidário, indispensável na construção de uma sociedade de direitos, ambientalmente justa e sustentável. 